\title{
THE EFFECT OF EXERCISE AND OF FOUR COMMONLY USED \\ DRUGS ON THE NORMAL HUMAN ELECTROCARDIOGRAM, WITH PARTICULAR REFERENCE TO T WAVE CHANGES
}

\author{
By ALFRED S. HARTWELL, JOHN B. BURRETT, ASHTON GRAYBIEL, \\ AND PAUL D. WHITE \\ (From the Cardiac Clinics and Laboratory, Massachusetts General Hospital, Boston)
}

(Received for publication February 2, 1942)

It is not yet sufficiently appreciated that there are many factors, aside from heart disease, which may affect the electrocardiogram. This is a matter of considerable importance for anyone making electrocardiographic interpretations. It becomes especially significant in those instances where the electrocardiogram is on the borderline of normality, or in attempting to evaluate the successive changes in electrocardiograms taken serially.

It is the $\mathrm{T}$ waves of the electrocardiogram which are most commonly and significantly affected by these extracardiac factors. A good example is digitalis, which may so alter the contour of the $\mathrm{S}-\mathrm{T}$ segments and $\mathrm{T}$ waves as to make interpretation difficult, unless it is known or suspected that the drug has been given. Significant $T$ wave changes may also result from the inhalation of tobacco smoke (1), alkalosis (2), and change in body position (3), merely to mention a few factors.

Recently we have taken a renewed interest in the effects of exercise and of certain commonly used drugs on the normal human electrocardiogram. Many of the studies in this connection have been carried out on animals (4 to 8 ), and few or none of the results are directly applicable to man, except as noted above. Furthermore, the results of the studies on man show no general agreement, and this has resulted in some confusion. Our plan of study has been simple and eminently practical, being designed more to demonstrate what changes occur than to show why.

\section{METHODS}

The effects of exercise, adrenaline, ergotamine tartrate, acetyl- $\beta$-methylcholine (mecholyl), and atropine sulfate were studied with reference to electrocardiographic changes in five normal subjects. Right carotid sinus pressure was studied in four subjects. The three classical leads were used. The subjects were all healthy males without heart disease. Their ages were $21,29,30,31$, and
38 years. All had normal electrocardiograms. Three were physicians and the other two were familiar with controlled laboratory procedures.

Each experiment was preceded by a period of rest until the pulse and blood pressure were stabilized. All the electrocardiograms were taken with the subject in the sitting position. Sufficient time was allowed between experiments for the effect of the previous procedure completely to disappear. Exercise and mecholyl were followed by three hours of rest before the next experiment was done. All the other tests were carried out on different days. A control tracing was taken after the subject had rested and immediately prior to starting each procedure. Repeated tracings were taken during the experiments at appropriate times (in order to obtain the maximum effect). Blood pressure, pulse, and respiratory rate, and general reaction were noted with each tracing, as well as the electrical axis of the QRS complexes.

\section{INDIVIDUAL PROCEDURES}

\section{Exercise}

A. Method. The electrocardiograms were taken before, during, and immediately after exercise, the subject sitting on an orthopedic exerciser, pumping, as on a bicycle, with the right leg. The tracings were taken after three and twelve minutes, while vigorous pumping was continued. Also, continuous tracings of Lead 2 were taken in three subjects, beginning just prior to stopping exercise and continuing for two minutes after all activity had ceased.

$B$. Results. Exercise lowered the $\mathrm{T}$ waves of Lead 2 in all electrocardiograms of the five subjects (Figure 1), though but slightly as a rule. The $T$ wave in Lead 1 was lowered in all but one subject; that particular $\mathrm{T}$ wave showed no change. The $T$ wave in Lead 3 was lowered in two subjects and was elevated in one subject (Table I).

C. Comment. Our finding that exercise lowers the $\mathrm{T}$ waves is contrary to current ideas generally held, based on records obtained after stopping exercise which are very different from those made 


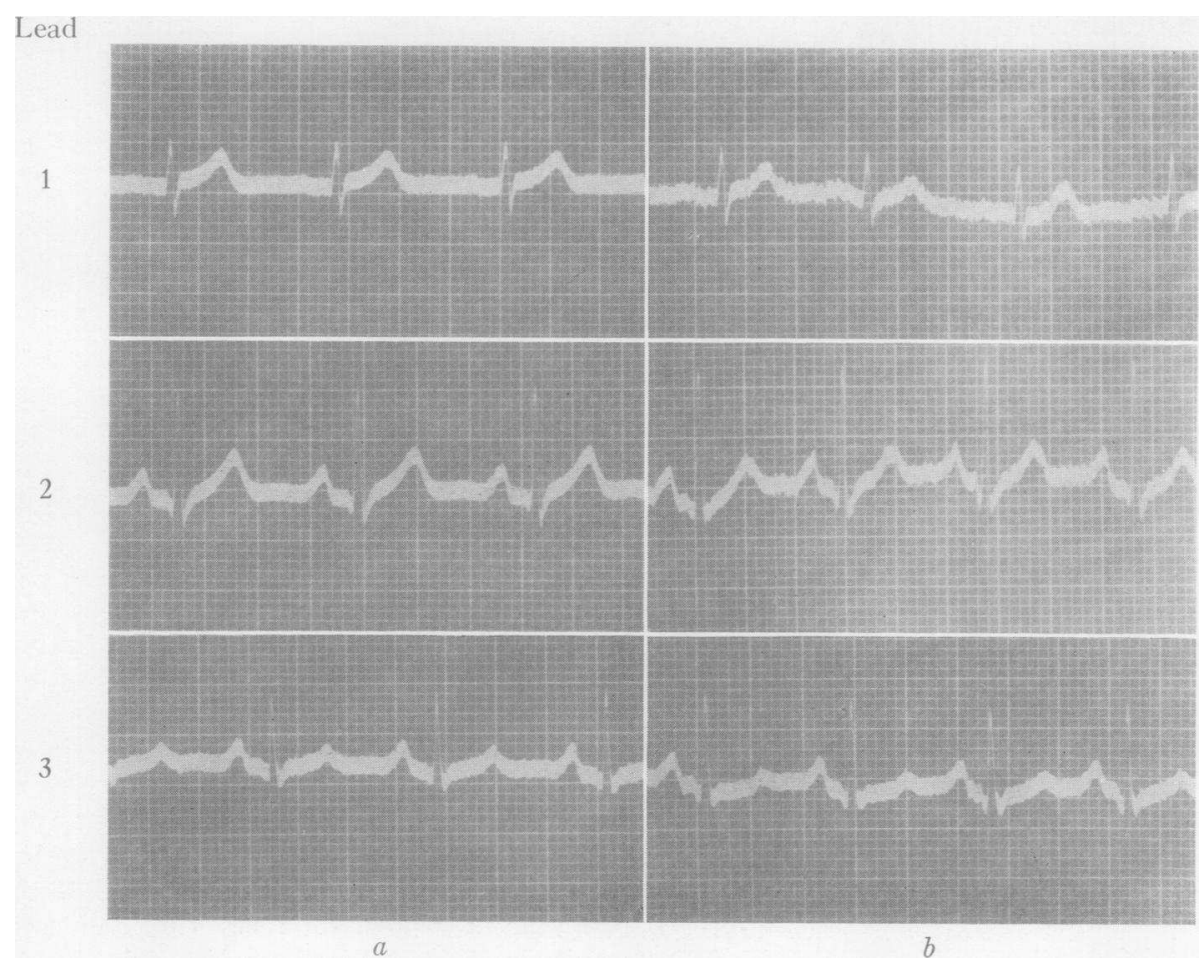

Fig. 1. EFFECT of Exercise

C. H. Column A taken during control period; column B, during exercise, 12 minutes after start. Leads $1,2,3$.

TABLE 1

Exercise

\begin{tabular}{|c|c|c|c|c|c|c|c|c|c|c|}
\hline \multirow[t]{2}{*}{ Subject } & \multicolumn{2}{|c|}{ J. B. B. } & \multicolumn{2}{|c|}{ A. S. H. } & \multicolumn{2}{|c|}{ G.S. } & \multicolumn{2}{|c|}{ J. R. G. } & \multicolumn{2}{|c|}{ C. H. } \\
\hline & Control & $\underset{\text { effect }}{\text { Maximum }}$ & Control & $\underset{\text { effect }}{\text { Maximum }}$ & Control & $\underset{\text { effect }}{\text { Maximum }}$ & Control & $\underset{\text { effect }}{\text { Maximum }}$ & Control & $\underset{\text { effect }}{\text { Maximum }}$ \\
\hline Pulse rate & 86 & 140 & 66 & 96 & 66 & 75 & 75 & 100 & 85 & 100 \\
\hline Blood pressure & $100 / 70$ & $115 / 75$ & $132 / 98$ & $155 / 90$ & $100 / 55$ & $125 / 70$ & $125 / 90$ & $150 / 90$ & $95 / 60$ & $125 / 60$ \\
\hline $\mathrm{T}-1\left(10^{-4} \text { volt }\right)^{*}$ & 3 & 2 & 4 & 3 & 3 & 3 & 4 & 3 & 2.75 & 2.25 \\
\hline $\mathrm{T}-2\left(10^{-4} \text { volt }\right)^{*}$ & 2.5 & 1.75 & 3.5 & 2.5 & 6 & 5.5 & 3.5 & 3 & 3.5 & 2.5 \\
\hline T-3 (10 -4 volt $)^{*}$ & -0.25 & -0.25 & -0.1 & -0.1 & 3 & 2 & -0.5 & 0 & 1.25 & 1 \\
\hline $\begin{array}{c}\text { QRS axis } \\
\text { (degrees by } \\
\text { Einthoven triangle) }\end{array}$ & +38 & +38 & +45 & +40 & +75 & +80 & +42 & +85 & +78 & +70 \\
\hline
\end{tabular}

* This is 10 to the minus fourth power, that is, a tenth of a millivolt.

during exercise. Joffe (9), for example, observed elevation of the $T$ waves in twenty-two normal subjects after exercise. Our findings are in agreement with those of v. Mentzingen (10) who, in studying the electrocardiograms of 451 subjects during exercise, noted lower $\mathrm{T}$ waves in 410 of them. Most of his subjects, however, had abnormal hearts. We wish to emphasize that our tracings were taken with the subject actually exercising and that within half a minute after the subject stopped motion, the lowered $\mathrm{T}$ waves began to return to (or surpass) their former height. 


\section{Adrenaline}

A. Method. One cc. of a 1:1000 solution of adrenaline hydrochloride was injected subcutaneously. One subject gave a history of marked response to adrenaline, so that $0.5 \mathrm{cc}$. was given to him. Tracings were taken five, ten, fifteen, twenty, and thirty minutes after the drug was administered.

$B$. Results. Adrenaline lowered all the $\mathrm{T}$ waves of the three leads in three subjects, while in the other two subjects all the $\mathrm{T}$ waves were lowered, except that in one subject $\mathrm{T}-1$ and in the other

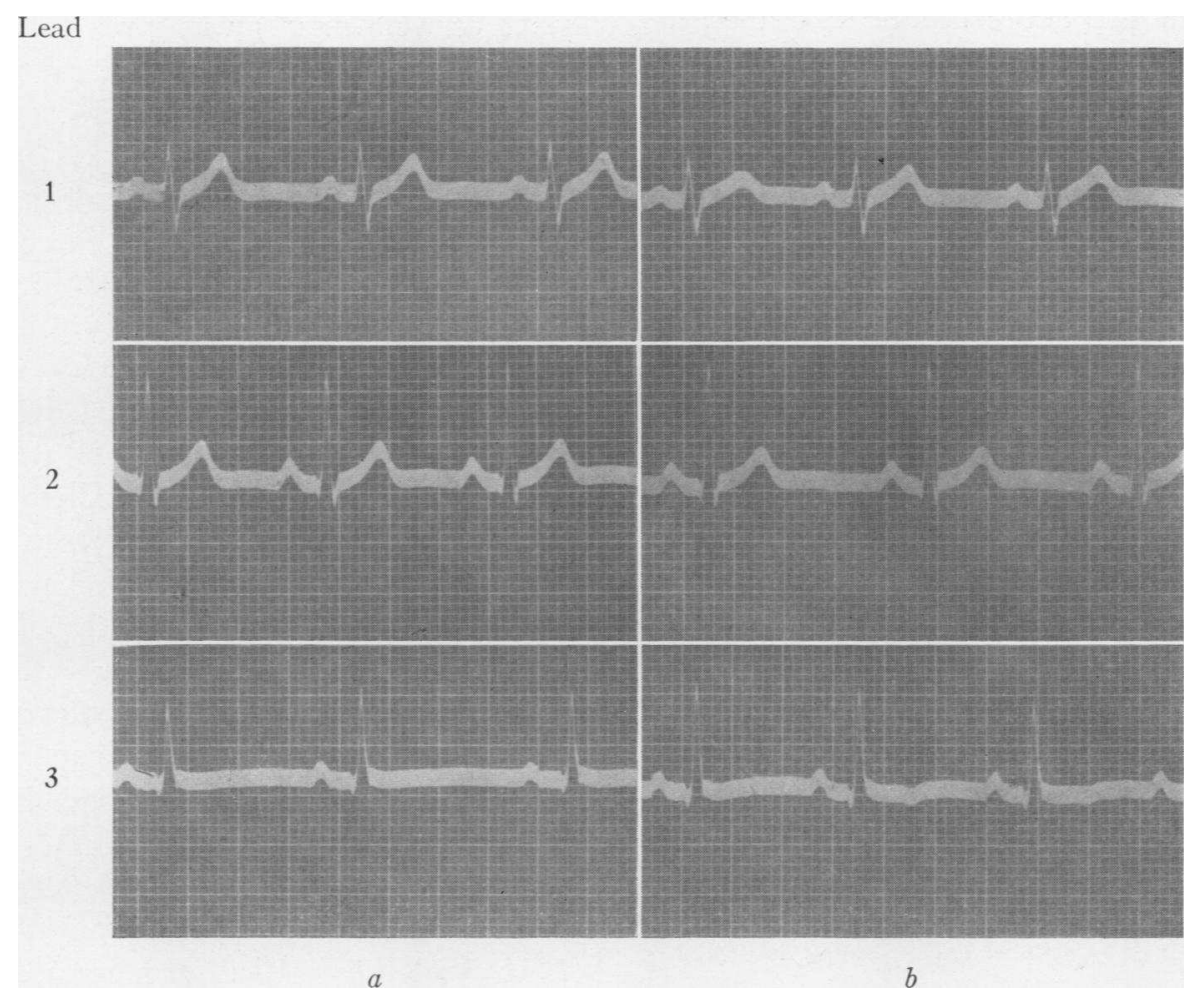

Fig. 2-A. Effect of Adrenaline

J. R. G. Column A taken during control period; column B, 22 minutes after adrenaline $\mathrm{HCl}, 1: 1000$ solution, $1 \mathrm{cc}$. subcutaneously. Leads 1, 2, 3.

TABLE II

Adrenaline hydrochloride

\begin{tabular}{|c|c|c|c|c|c|c|c|c|c|c|}
\hline \multirow[t]{2}{*}{ Subject } & \multicolumn{2}{|c|}{ J. B. B. } & \multicolumn{2}{|c|}{ A. S. H. } & \multicolumn{2}{|c|}{ G.S. } & \multicolumn{2}{|c|}{ J. R. G. } & \multicolumn{2}{|c|}{ C. H. } \\
\hline & Control & $\underset{\text { effect }}{\text { Maximum }}$ & Control & $\underset{\text { effect }}{\text { Maximum }}$ & Control & $\underset{\text { effect }}{\text { Maximum }}$ & Control & $\underset{\text { effect }}{\text { Maximum }}$ & Control & $\underset{\text { effect }}{\text { Maximum }}$ \\
\hline Pulse rate & 75 & 92 & 72 & 70 & 60 & 66 & 75 & 86 & 85 & 80 \\
\hline Blood pressure & $110 / 70$ & $120 / 55$ & $130 / 95$ & $150 / 80$ & $110 / 60$ & $145 / 60$ & $125 / 80$ & $120 / 60$ & $95 / 55$ & $110 / 50$ \\
\hline $\mathrm{T}-1$ & 2.5 & 2 & 2.5 & 2 & 2.5 & 2.5 & 3 & 2 & 2.25 & 2 \\
\hline $\mathrm{T}-2$ & 3 & 2.25 & 2 & 1.5 & 4.75 & 4 & 3 & 2 & 3.5 & 2 \\
\hline $\mathrm{T}-3$ & -0.5 & -0.5 & -1 & -1.5 & 2.5 & 2 & 0 & -1 & 1 & 0.5 \\
\hline QRS axis & +38 & +42 & +50 & +50 & +68 & +68 & +70 & +70 & +75 & +68 \\
\hline
\end{tabular}


T-3 showed no change (Figure 2-A and Table II). The effect was maximal in ten to fifteen minutes. One subject was given $1 \mathrm{cc}$. of a $1: 100,000$ solution of adrenaline intravenously. This resulted in marked lowering of the $\mathrm{T}$ wave, with transient inversion; Lead 2 only was recorded in this experiment (Figure 2-B). One subject showed frequent ventricular premature beats, while another showed a varying $\mathrm{P}-\mathrm{R}$ interval with inverted $\mathrm{P}$ waves for a few minutes after adrenaline. Arrhythmias under adrenaline have been noted by others (11).

C. Comment. Our finding of lowered $\mathrm{T}$ waves due to adrenaline is in agreement with that of Clough (12), who studied the effect of 7.5 minims of $1: 1000$ adrenaline intramuscularly in normal males and in subjects with irritable hearts. $\mathrm{He}$ found a decrease of 1 to $2 \mathrm{~mm}$. in the $\mathrm{T}$ waves. Levine et al. (13) gave the same dose as we to ten normals and stated that "in young adults there was an average fall in the $T$ wave amplitude in Lead 2 of $0.8 \mathrm{~mm}$., five cases showing an in-

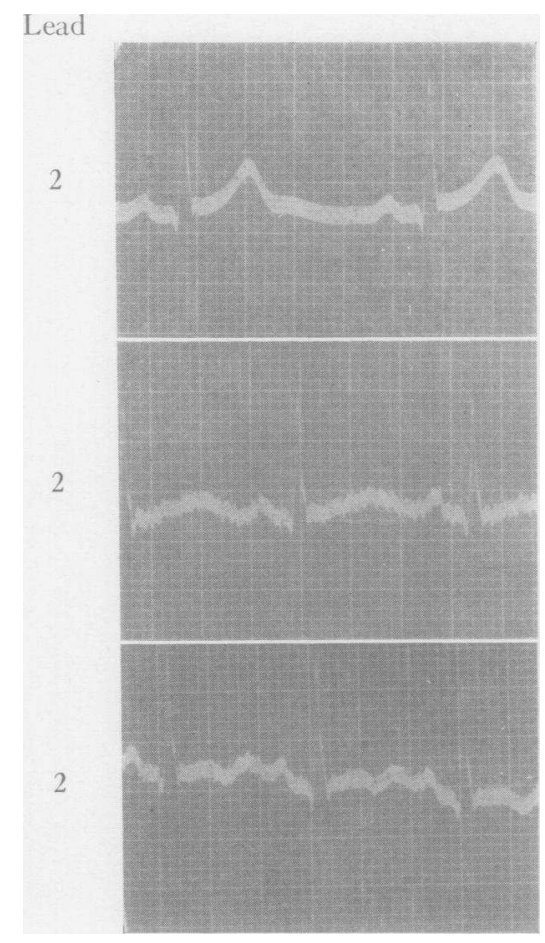

Fig. 2-B. Effect of Adrenaline

A. S. H. During administration of adrenaline $\mathrm{HCl}$, $0.01 \mathrm{mgm}$. (1 cc. of $1: 100,000$ solution) intravenously; control, beginning effect, maximal effect. Leads 2, 2, 2. crease from 0.4 to $1.5 \mathrm{~mm}$. and five a decrease of from 1.5 to $3.3 \mathrm{~mm}$."

\section{Ergotamine tartrate}

A. Method. One cc. of ergotamine tartrate (1 mgm.) was given subcutaneously to two subjects, but, due to marked nausea in those cases, only $0.5 \mathrm{cc}$. $(0.5 \mathrm{mgm}$.) was given to the others. Tracings were taken five, fifteen, thirty, and, in three subjects, sixty minutes after the drug was given.

B. Results. Ergotamine raised all the $\mathrm{T}$ waves of the three leads of five subjects, except that T-2 in one subject showed no change ${ }^{1}$ (Figure 3 and Table III). The effect was maximal in thirty to sixty minutes.

C. Comment. Almost identical results have been obtained by Nordenfelt (14) with twenty normals, using $1 \mathrm{cc}$. (1 mgm.). There is considerable evidence that ergotamine opposes the action of adrenaline $(8,15,16,17)$. We have observed that exercise, which stimulates the sympathetic nervous system, and adrenaline, lower the $\mathrm{T}$ waves, and therefore the opposite effect of raising the $T$ waves was of considerable interest. The elevation of the $T$ waves was obtained without marked slowing of the pulse.

\section{Atropine sulfate}

A. Method: One-fiftieth of a grain of atropine sulfate was given subcutaneously. Marked dryness of the mouth was noted in each subject after about forty minutes. Tracings were taken twenty, forty, sixty and ninety minutes after the drug was given.

B. Results. Atropine lowered all the $\mathrm{T}$ waves of the three leads in three subjects. It lowered all the $T$ waves except $T-1$ in one subject and all but $\mathrm{T}-3$ in another subject (Figure 4 and Table IV). One subject developed A-V nodal rhythm twenty minutes after the atropine injection. By forty minutes this had changed to sinus tachycardia. Wilson (18) and Lewis (19) have noted this as an early action of atropine in normals.

C. Comment. Atropine significantly lowers the $\mathrm{T}$ waves, as shown by two of us already in a previous paper (1). Its action is to inhibit the parasympathetic nervous system, particularly the vagus.

\footnotetext{
1 In this case $\mathrm{T}-1$ and $\mathrm{T}-3$ showed only minute changes.
} 
TABLE III

Ergotamine tartrate

\begin{tabular}{|c|c|c|c|c|c|c|c|c|c|c|}
\hline \multirow[t]{2}{*}{ Subject } & \multicolumn{2}{|c|}{ J. B. B. } & \multicolumn{2}{|c|}{ A. S. H. } & \multicolumn{2}{|c|}{ G.S. } & \multicolumn{2}{|c|}{ J. R. G. } & \multicolumn{2}{|c|}{ C. H. } \\
\hline & Control & $\underset{\text { effect }}{\text { Maximum }}$ & Control & $\underset{\text { effect }}{\text { Maximum }}$ & Control & $\underset{\text { effect }}{\text { Maximum }}$ & Control & $\begin{array}{c}\text { Maximum } \\
\text { effect }\end{array}$ & Control & $\underset{\text { effect }}{\text { Maximum }}$ \\
\hline Pulse rate & 75 & 66 & 66 & 66 & 66 & 50 & 85 & 66 & 75 & 66 \\
\hline Blood pressure & $115 / 70$ & $105 / 80$ & $135 / 85$ & $148 / 108$ & $100 / 60$ & $100 / 60$ & $120 / 70$ & $110 / 80$ & $95 / 60$ & $90 / 60$ \\
\hline $\mathrm{T}-1$ & 2.5 & 3 & 2.5 & 4 & 2 & 2.5 & 3.25 & 4.5 & 2 & 3.25 \\
\hline $\mathrm{T}-2$ & 3.5 & 3.5 & 1.5 & 2.5 & 3.5 & 6.5 & 3.25 & 4.5 & 2.5 & 4.5 \\
\hline $\mathrm{T}-3$ & 0.5 & 1 & -1 & 0.5 & 2 & 3.75 & -1.5 & -0.75 & 0.5 & 2 \\
\hline QRS axis & +44 & +48 & +42 & +42 & +72 & +78 & +64 & +60 & +60 & +72 \\
\hline
\end{tabular}

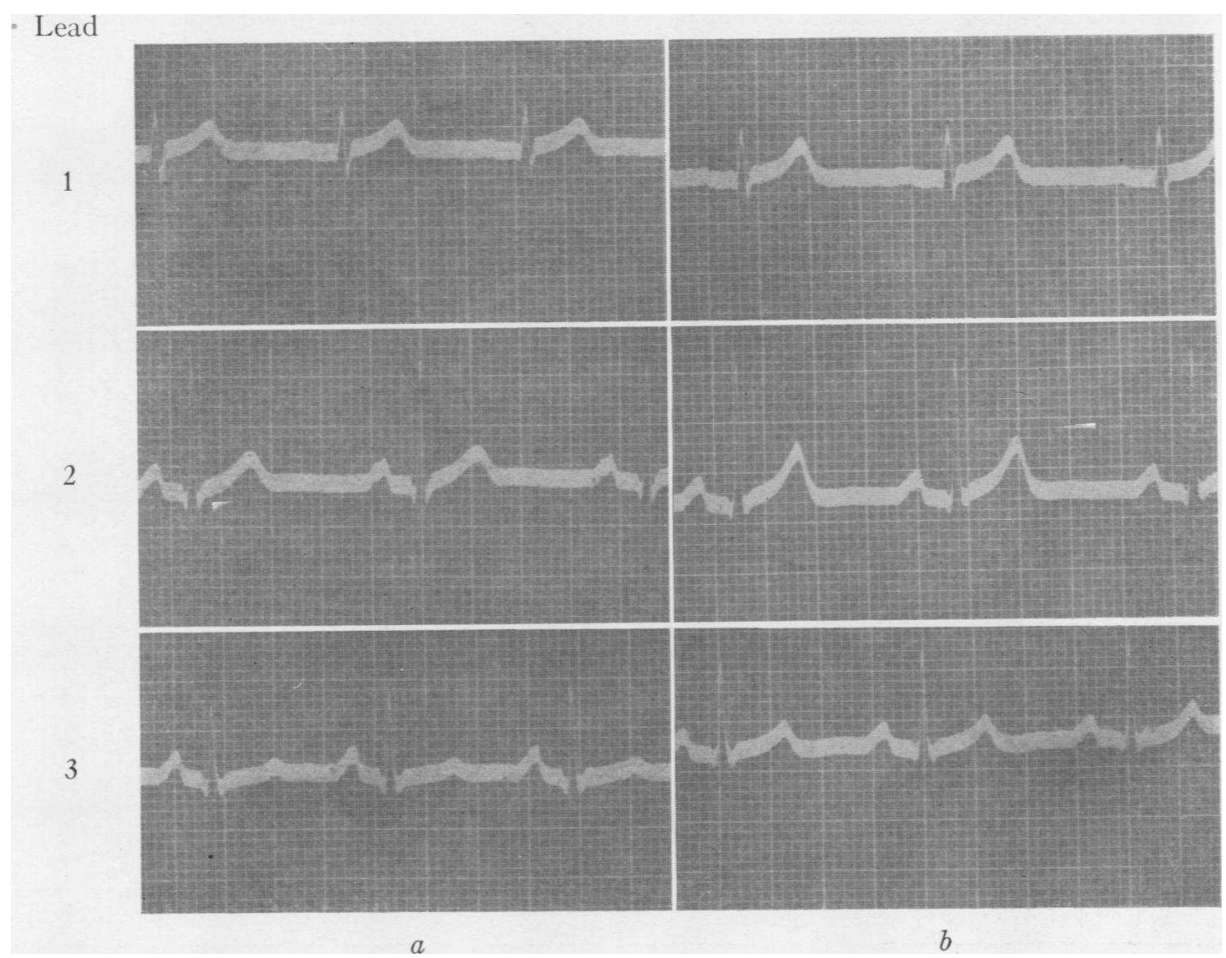

Fig. 3. Effect of Ergotamine

C. H. Column A taken during control period; column B, 45 minutes after ergotamine tartrate, $0.5 \mathrm{mgm}$. subcutaneously. Leads $1,2,3$.

Thus drugs which increase sympathetic tone or inhibit parasympathetic activity lower the $T$ waves, while those which lower sympathetic tone, such as ergotamine, raise the $\mathrm{T}$ waves.

\section{Mecholyl}

A. Method. Two subjects received $25 \mathrm{mgm}$. of mecholyl subcutaneously, but the general reaction was so marked that $15 \mathrm{mgm}$. was given to the others. The latter group obtained a satisfactory response with sweating, salivation, diffuse blushing, and, as has been noted by many others, tachycardia.

B. Results. Mecholyl lowered all the $\mathrm{T}$ waves in the three leads of all five subjects. All subjects developed tachycardia, beginning one to one and 


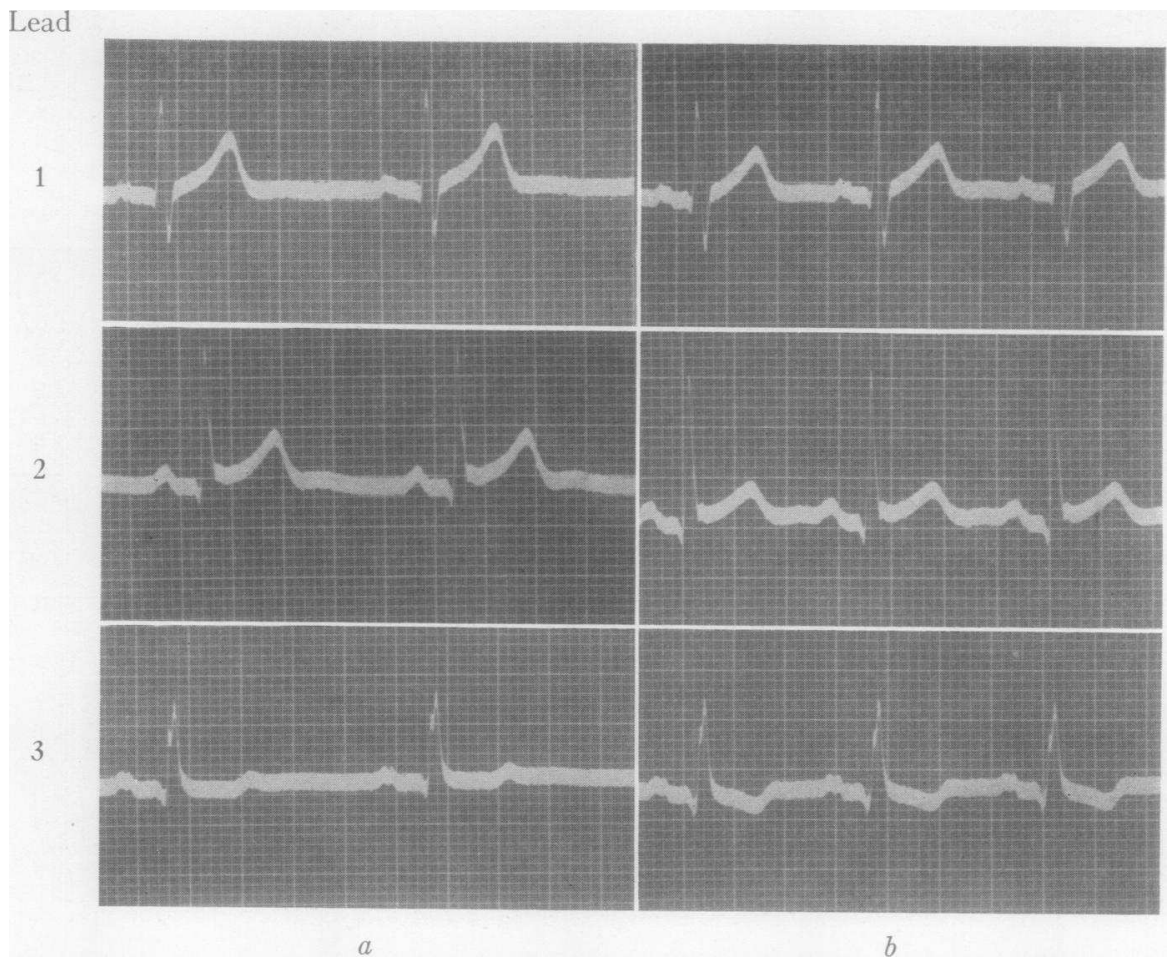

Fig. 4. Effect of Atropine

A. S. H. Column A taken during control period; column B, 60 minutes after atropine sulphate, $1.3 \mathrm{mgm}$. (1/50 gr.) subcutaneously. Leads $1,2,3$.

TABLE IV

Atropine sulfate

\begin{tabular}{|c|c|c|c|c|c|c|c|c|c|c|}
\hline \multirow[t]{2}{*}{ Subject } & \multicolumn{2}{|c|}{ J. B. B. } & \multicolumn{2}{|c|}{ A. S. H. } & \multicolumn{2}{|c|}{ G. S. } & \multicolumn{2}{|c|}{ J. R. G. } & \multicolumn{2}{|c|}{ C. H. } \\
\hline & Control & $\underset{\text { effect }}{\text { Maximum }}$ & Control & $\underset{\text { effect }}{\text { Maximum }}$ & Control & $\underset{\text { effect }}{\text { Maximum }}$ & Control & $\underset{\text { effect }}{\text { Maximum }}$ & Control & $\underset{\text { effect }}{\text { Maximum }}$ \\
\hline Pulse rate & 86 & 100 & 60 & 86 & 66 & 86 & 70 & 86 & 85 & 100 \\
\hline Blood pressure & $115 / 70$ & $100 / 60$ & $120 / 88$ & $140 / 95$ & $100 / 60$ & $100 / 60$ & $120 / 75$ & $110 / 70$ & $100 / 60$ & $90 / 55$ \\
\hline $\mathrm{T}-1$ & 2.5 & 1.5 & 6 & 4 & 2.5 & 2 & 3.5 & 3 & 1.75 & 2 \\
\hline $\mathrm{T}-2$ & 3 & 2 & 5 & 2.5 & 4.5 & 3 & 4.5 & 4 & 3 & 2.75 \\
\hline $\mathrm{T}-3$ & 0.25 & 0 & 1 & -1.5 & 2.25 & 1 & 0.25 & 0.75 & 1.5 & 1 \\
\hline QRS axis & +50 & +58 & +58 & +58 & +74 & +74 & +58 & +70 & +72 & +84 \\
\hline
\end{tabular}

a half minutes after administration. Four subjects showed a fall in blood pressure (Figure 5 and Table V).

C. Comment. Mecholyl, supposedly a parasympathetic stimulant par excellence, has been found to cause tachycardia by all its users (20 to 24 ). This seemingly paradoxical effect on the heart has been discussed ably by others (23). Rothberger (25), giving acetyl choline intravenously to cats, noted an initial transient slowing followed by tachycardia. Accordingly, we took continuous tracings of Lead 2, starting before injection of mecholyl and continuing until the tachycardia was well started, but observed no preliminary slowing 


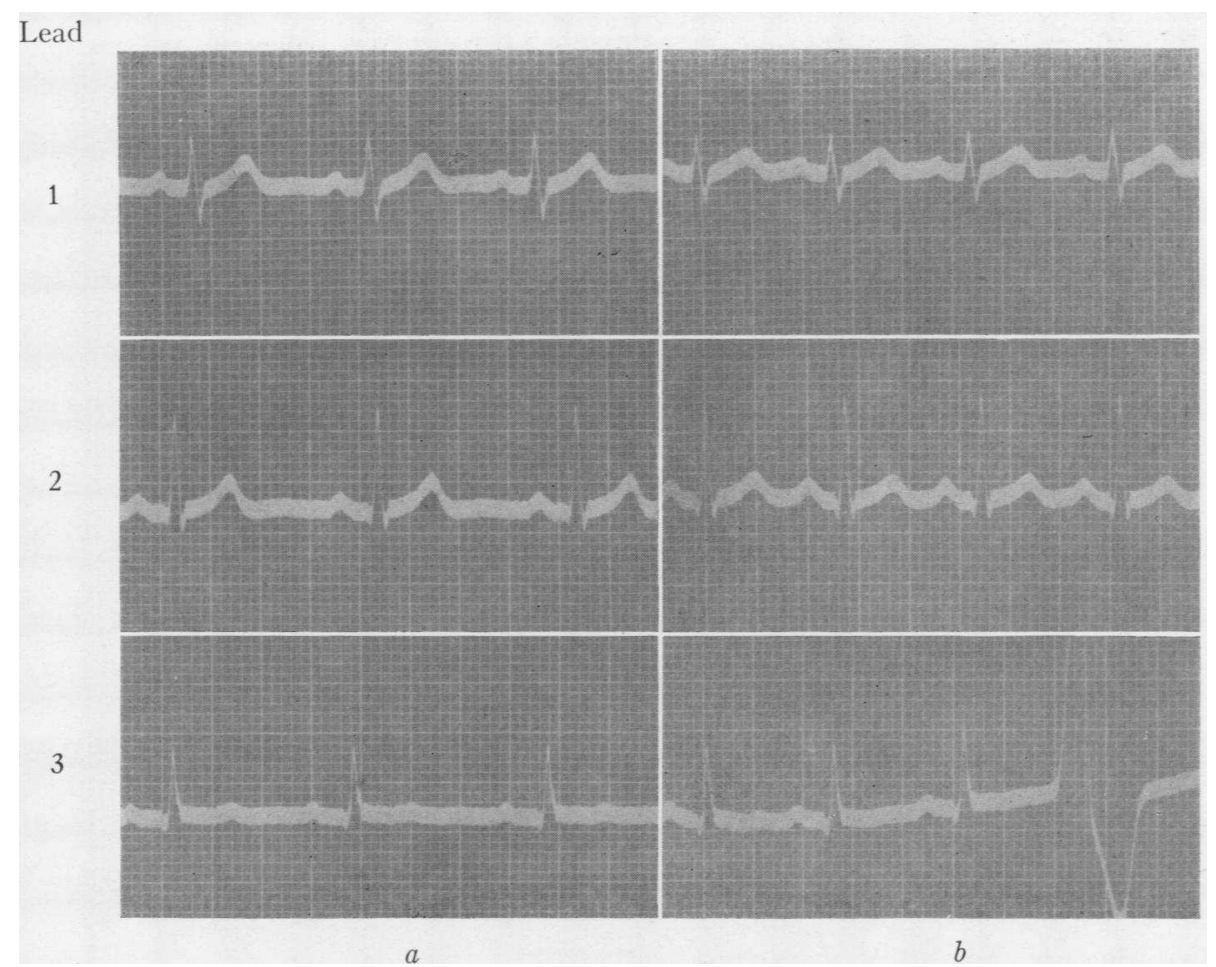

Fig. 5. Effect of Mecholyl

J. R. G. Column A taken during control period; column B, 2 minutes after mecholyl, $15 \mathrm{mgm}$. subcutaneously. Leads $1,2,3$.

TABLE V

Mecholyl

\begin{tabular}{|c|c|c|c|c|c|c|c|c|c|c|}
\hline \multirow[t]{2}{*}{ Subject } & \multicolumn{2}{|c|}{ J. B. B. } & \multicolumn{2}{|c|}{ A. S. H. } & \multicolumn{2}{|c|}{ G.S. } & \multicolumn{2}{|c|}{ J. R. G. } & \multicolumn{2}{|c|}{ C. $\mathrm{H}$. } \\
\hline & Control & $\underset{\text { effect }}{\text { Maximum }}$ & Control & $\underset{\text { effect }}{\text { Maximum }}$ & Control & $\underset{\text { effect }}{\text { Maximum }}$ & Control & $\underset{\text { effect }}{\text { Maximum }}$ & Control & $\underset{\text { effect }}{\text { Maximum }}$ \\
\hline Pulse rate & 86 & 120 & 60 & 140 & 66 & 90 & 75 & 110 & 85 & 100 \\
\hline Blood pressure & $115 / 70$ & $120 / 70$ & $135 / 90$ & $150 / 95$ & $100 / 60$ & $100 / 60$ & $120 / 70$ & $110 / 60$ & $100 / 60$ & $80 / 50$ \\
\hline $\mathrm{T}-1$ & 2.5 & 2 & 4 & 1.5 & 2 & 1.5 & 2.5 & 1.5 & 2.5 & 1.75 \\
\hline $\mathrm{T}-2$ & 2 & 1 & 3 & 0 & 4.5 & 3 & 2.5 & 1.25 & 2.75 & 2.5 \\
\hline $\mathrm{T}-3$ & 0 & -0.25 & -1.5 & -3 & 2.5 & 1.75 & 0.25 & 0 & 1 & 0.75 \\
\hline QRS axis & +50 & +50 & +60 & +90 & +75 & +70 & +70 & +75 & +72 & +85 \\
\hline
\end{tabular}

of the heart rate. We are unable to explain the paradoxical tachycardia and lowering of the $\mathrm{T}$ waves. .

\section{Right carotid sinus pressure}

A. Method. This was tried on four subjects. No observations were made on the blood pressure in these experiments.
$B$. Results. All subjects showed slowing of the pulse. There was an increase of the amplitude of all the $T$ waves in Lead 3 of the five subjects. The $T$ waves in Lead 1 and Lead 2 were elevated in two of the subjects. One Lead 1 showed a decrease in the $\mathrm{T}$ wave (Table VI).

C. Comment. The predominant action of carotid sinus pressure on the electrocardiogram, aside 
TABLE VI

Right carotid sinus pressure

\begin{tabular}{|c|c|c|c|c|c|c|c|c|}
\hline \multirow{2}{*}{ Subject } & \multicolumn{2}{|c|}{ J. B. B. } & \multicolumn{2}{|c|}{ A.S. H. } & \multicolumn{2}{|c|}{ J. R. G. } & \multicolumn{2}{|c|}{ C. $\mathrm{H}$. } \\
\hline & $\begin{array}{c}\text { Con- } \\
\text { trol }\end{array}$ & $\underset{\text { mumi- }}{\text { Mamect }}$ & $\begin{array}{l}\text { Con- } \\
\text { trol }\end{array}$ & $\begin{array}{l}\text { Maxi- } \\
\text { mum } \\
\text { effect }\end{array}$ & $\begin{array}{l}\text { Con- } \\
\text { trol }\end{array}$ & $\begin{array}{c}\text { Maxi- } \\
\text { mum } \\
\text { effect }\end{array}$ & $\begin{array}{c}\text { Con- } \\
\text { trol }\end{array}$ & $\begin{array}{l}\text { Maxi- } \\
\text { mum } \\
\text { effect }\end{array}$ \\
\hline Pulse rate & 86 & 77 & 70 & 55 & 75 & 66 & 85 & 66 \\
\hline$T-1$ & 3 & 3 & 3.5 & 4 & 4 & 3.5 & 2.75 & 3 \\
\hline $\mathrm{T}-2$ & 2.5 & 3 & 3 & 4.5 & 3.5 & 3.5 & 3 & 3 \\
\hline $\mathrm{T}-3$ & -0.5 & 0.25 & -1 & 0 & -0.5 & 0 & 1 & 1.25 \\
\hline QRS axis & +38 & +40 & +45 & +45 & +42 & +50 & +78 & +75 \\
\hline
\end{tabular}

from slowing of the rate, is to raise the $\mathrm{T}$ waves. These results may be considered as agreeing with the concept that factors which inhibit sympathetic tone or increase the vagal tone raise the $T$ waves.

\section{DISCUSSION}

The vague conceptions in the minds of most physicians, both in general and in particular, about the effects of these various procedures and of autonomic nervous influences on the electrocardiogram, will, we hope, be clarified by this report. The importance of our findings is also of a practical nature. For instance, if a "repeat" electrocardiogram is taken on a patient who receives atropine, or adrenaline, or mecholyl, shortly before the second tracing, $T$ wave changes would be noted and might be interpreted as a change in the basic cardiac status, when in reality they are due to the effect of the drug. These drugs are commonly used in hospital practice and it was in part for this reason that the present study was made.

Interesting speculations have been mentioned regarding the sympathetic and parasympathetic nervous systems and the part they may play in affecting the electrocardiogram. Of the exact nature of the part they play in these results, we are not sure. Indeed, in the intact normal subject, compensatory mechanisms probably play important roles in determining the final result. Our findings suggest, however, that adrenergic factors lower the $\mathrm{T}$ waves and cholinergic factors raise them. The anomalous action of mecholyl has been discussed. It may also be postulated from our results that procedures which elevate the pulse rate, lower the $\mathrm{T}$ waves, and vice versa. That this is true, there is no doubt. However, in some of the sulljects with no change in pulse rate, the effect on the electrocardiogram was no less marked. This was particularly true in the case of adrenaline and ergotamine.

\section{SU M M ARY}

1. Exercise lowers the $T$ waves of the normal human electrocardiogram, with return toward normal in less than a minute. During recovery the amplitude of $\mathrm{T}$ may be greater than normal.

2. Adrenaline lowers the $T$ waves. The effect lasts from fifteen to thirty minutes.

3. Ergotamine tartrate raises the $T$ waves. This effect lasts as long as an hour.

4. Atropine lowers the $T$ waves. The effect is maximal in one hour but may last ninety minutes.

5. Mecholyl lowers the $\mathrm{T}$ waves and causes tachycardia without preliminary bradycardia.

6. Right carotid sinus pressure causes an elevation of the $T$ waves.

7. The importance of taking these changes into account when interpreting electrocardiograms is stressed.

\section{BIBLIOGRAPHY}

1. Graybiel, A., Starr, R. S., and White, P. D., Electrocardiographic changes following the inhalation of tobacco smoke. Am. Heart J., 1938, 15, 89.

2. Barker, P. S., Shrader, E. L., and Ronzoni, E., The effects of alkalosis and of acidosis upon the human electrocardiogram. Am. Heart J., 1939, 17, 169.

3a. Scherf, D., and Weissberg, J., The alterations of the $\mathrm{T}$-waves caused by a change of posture. Am. J. Med. Sc., 1941, 201, 693.

b. White, P. D., Chamberlain, F. L., and Graybiel, A., Inversion of the $\mathrm{T}$ waves in Lead II caused by a variation in position of the heart. Brit. Heart J., 1941, 3, 233.

4. Douglas, A. H., Gelfand, B., and Shookhoff, C., Production by epinephrine of $\mathrm{S}-\mathrm{T}$ changes in the electrocardiogram of the cat, similar to those of coronary occlusion. Am. Heart J., 1937, 14, 211.

5. Milles, G., and Smith, P. W., Effects of epinephrine on the heart. Am. Heart J., 1937, 14, 198.

6. Bartos, E., and Burstein, J., Can variations in ventricular systole be determined from electrocardiogram deflections? J. Lab. and Clin. Med., 1924, 9, 217.

7. Hoff, H. E., and Nahum, L. H., The role of adrenaline in the production of ventricular rhythms and their suppression by acetyl- $\beta$-methycholine chloride. J. Pharmacol. and Exper. Therap., 1934, 52, 235.

8. Youmans, J. B., and Trimble, W. H., Experimental and clinical studies of ergotamine; the effect of ergotamine on the heart rate of trained unanes- 
thetized dogs. J. Pharmacol. and Exper. Therap., 1930, 38, 133.

9. Joffe, E., La modification de l'électrocardiogramme humain par l'effort. Compt. rend. Soc. de biol., 1938, 128, 809.

10. v. Mentzingen, A., Die Bedeutung der Veränderung der Nachschwankung des Elektrokardiogramms nach Belastung für die Beurteilung der Funktion des Herzens. Klin. Wchnschr., 1934, 13, 88.

11. Hume, W. E., The action of adrenalin chloride on the human heart. Quart. J. Med., 1928, 21, 459.

12. Clough, H. D., Studies on Epinephrin III ; Effect of epinephrin on the electrocardiograms of patients with "irritable heart." Arch. Int. Med., 1919, 24, 284.

13. Levine, S. A., Ernstene, A. C., and Jacobson, B. M., The use of epinephrine as a diagnostic test for angina pectoris. Arch. Int. Med., 1930, 45, 191.

14. Nordenfelt, O., Die Ekg-Veränderungen bei orthostatischen Kreislaufstörungen und Ergotamintartrat. Ztschr. f. Kreislauforsch., 1939, 31, 761.

15. Kolm, R., and Pick, E. P., Uber die Bedeutung des Calciums für die Erregbarkeit der sympathischen Herznervenendigungen. Arch. f. d. ges. Physiol., 1921, 189, 137.

16. Jang, C-S., The potentiation and paralysis of adrenergic effects by ergotoxine and other substances. J. Pharmacol. and Exper. Therap., 1941, 71, 87.

17. Goodman, L., and Gilman, A., The Pharmacological Basis of Therapeutics. The Macmillan Co., New York, 1941, p. 340.
18. Wilson, F. N., The production of atrioventricular rhythm in man after the administration of atropin. Arch. Int. Med., 1915, 16, 989.

19. Lewis, Sir Thomas, The Mechanism and Graphic Registration of the Heart Beat. Shaw and Sons, Ltd., London, 1925, p. 196, 3rd edition.

20. Starr, I., Elsom, K. A., Reisinger, J. A., and Richards, A. N., Acetyl- $\boldsymbol{\beta}$-methylcholin; the action on normal persons with note on the action of ethyl ether of $\beta$-methylcholin. Am. J. M. Sc., 1933, 186, 313.

21. Page, I. H., Acetyl- $\beta$-methylcholine (mecholin). Observations concerning its action on blood pressure, skin temperature, and heart, as exhibited by the electrocardiogram of hypertensive patients. Am. J. M. Sc., 1935, 189, 55.

22. Kovacs, J., Saylor, L. L., and Wright, I. S., The pharmacological and therapeutic effects of certain choline compounds. Am. Heart J., 1936, 11, 53.

23. Dameshek, W., Loman, J., and Myerson, A., Human autonomic pharmacology; the effect on the normal cardiovascular system of acetyl- $\beta$-methylcholine chloride, atropine, prostigmin and benzedrine-with especial reference to the electrocardiogram. Am. J. M. Sc., 1938, 195, 88.

24. Weiss, S., and Ellis, L. B., The comparative effects of the intravenous administration to man of acetylcholine and acetyl- $\beta$-methylcholine. J. Pharmacol. and Exper. Therap., 1934, 52, 113.

25. Goldenberg, M., and Rothberger, C. J., Uber die Wirkung von Acetylcholin auf das Warmblüterherz. Ztschr. f. d. ges. exper. Med., 1934, 94, 151. 